\title{
Frequência de brucelose bovina em rebanhos leiteiros e em seres humanos na região central do estado do Maranhão, Brasil
}

\author{
Frequency of brucellosis in bovine livestock dayre \\ and humans in central region of the state of Maranhão, Brazil
}

\author{
Robert Ferreira Barroso de Carvalho ${ }^{1 *}$, Hamilton Perreira Santos ${ }^{2}$, Luís Antonio Mathias ${ }^{3}$, Hélder de \\ Moraes Pereira², Adriana Prazeres Paixão', Valter Marchão Costa Filho', Lúcia Maria Côelho Alves ${ }^{2}$
}

| | | | | | | | | | | | | | | | | | | | | | | | | | | | | | | | | | | | | | | | | | | | | | | | | | | | | | | | | | | | | | | | | | | | | | | | | | | | | | | | | | | | | | | | | | | | | | | | | | | | | | | | | | | | | | | | | | | | | | | | | | | | | | | | | | | | | | | | | | | | | | | | | | | | | | | | | | | | | | | | | | | | | | | | | | | | | | | | | | | | | | | | | | | | | | | | | | | | | | |

RESUMO: Objetivou-se com este estudo estimar a frequência da brucelose em bovinos e em ordenhadores na região central do Maranhão. Foram escolhidas, no período de maio a outubro de 2013, de forma aleatória, 35 propriedades cadastradas na Agência Estadual de Defesa Agropecuária do Maranhão (AGED-MA) e analisados sorologicamente 525 bovinos com aptidão leiteira, hemossoros de 60 ordenhadores, além de ter sido aplicado questionário epidemiológico para investigar os fatores de risco associados à infecção. $\mathrm{O}$ protocolo de diagnóstico utilizado foi o teste de triagem com antígeno acidificado tamponado (AAT), e a confirmaçáo dos reagentes ocorreu mediante os testes 2-mercaptoetanol (2-ME) e polarizaçáo fluorescente (TPF). A frequência de animais sororreagentes foi de 26/525 (4,95\%) no teste AAT e 17/525 (3,23\%) e 13/525 (2,47\%) nos testes de 2-ME e TPF, respectivamente. A frequência de rebanhos foco, com pelo menos um animal soropositivo, foi de 9/35 $(25,71 \%)$ e $8 / 3(22,85 \%)$, nessa ordem. Referente aos ordenhadores, $1 / 60(1,66 \%)$ foi reagente nos testes confirmatórios de 2-ME, TPF e fixação de complemento. $\mathrm{O}$ fator de risco associado à ocorrência da brucelose, na análise multivariada, foi presença de ovinos (odds ratio - OR=6,66; intervalo de confiança de 95\% - IC95\% 1,26$35,03)$. O estudo demonstrou que a brucelose está disseminada no rebanho leiteiro investigado, indicando a necessidade de melhorias nas açôes de controle e erradicação da brucelose na regiáo estudada.

PALAVRAS-CHAVE: Brucella abortus; zoonoses; aborto; doença ocupacional; bursite; Maranhão.

\begin{abstract}
The aim of this study was to estimate the frequency of bovine and human brucellosis in the middle region of Maranhão. Thirty-five properties, registered at Maranhão State Agency of Agriculture Defense (AGED-MA), were chosen randomly, between May and October of 2013. Then, 525 blood serum samples from dairy cattle and 60 from milkers were serologically analyzed and went through an epidemiological questionnaire to investigate the risk factors associated to the infection. The diagnosis protocol used was the trial test of rose Bengal test (RBT), and the confirmation of reactors was by 2-mercaptoethanol (2-ME) and fluorescence polarisation assay (FPA). The frequency of animals that tested positive was $26 / 525$ $(4.95 \%)$ at RBT, and $17 / 525(3.23 \%)$ and $13 / 525(2.47 \%)$ at 2-ME and FPA, respectively. The frequencies of foci herds, with at least one positive animal, were $9 / 35$ (25.71\%) and 8/3 (22.85\%), respectively. Regarding the milkers, $1 / 60(1.66 \%)$ reacted at the confirmatory tests such as 2-ME, FPA and complement fixation. The risk factor, associated to brucellosis occurrence, in the multivariate analysis, was the presence of sheep (odds ratio - OR $=6.66$, confidence interval $-95 \% \mathrm{CI}=1.26-35.03$ ). The study showed that brucellosis is disseminated in the investigated dairy herd, indicating the need of a better control and eradication actions forbrucellosis in the examined region.
\end{abstract}

KEYWORDS: Brucella abortus; zoonoses; abortion; occupational disease; bursitis; Maranhão.

'Agência Estadual de Defesa Agropecuária do Maranhão (AGED-MA) - São Luís (MA), Brasil.

${ }^{2}$ Faculdade de Medicina Veterinária, Universidade Estadual do Maranhão (UEMA) - São Luís (MA), Brasil.

${ }^{3}$ Faculdade de Ciências Agrárias e Veterinária, Universidade Estadual Paulista “Júlio de Mesquita Filho" (UNESP) - Jaboticabal (SP), Brasil.

*Autor correspondente: rfbcarvalho@bol.com.br

Recebido em: 29/12/2014. Aceito em: 28/09/2016 


\section{INTRODUÇÃO}

A brucelose é uma doença infectocontagiosa crônica causada pela bactéria Brucella spp. que acomete diversas espécies domésticas, silvestres e o homem. Causa perdas econômicas e sociais ao sistema produtivo, além de ocasionar agravos à saúde da população.

Atualmente no gênero Brucella spp. há citação de 10 espécies, cada uma com hospedeiro preferencial: $B$ a abortus (bovinos); B. melitensis (caprinos e ovinos); B. suis (suínos); B. canis (caninos); B. ovis (ovinos); B. neotomae (rato-do-deserto, Neotoma Lepida); B. microti (camundongo-do-campo, Microtus Arvalis); B. ceti (cetáceos - golfinhos e baleias); B. pinnipedialis (penípedes - focas) e B. inopinata (homem). Exceto B. neotomae e $B$. ovis, todas as espécies são capazes de infectar o homem (GoMes, 2014).

A transmissão do agente etiológico ocorre primariamente pela ingestão de materiais contaminados, e a introdução no rebanho dá-se pela entrada de animais assintomáticos cronicamente infectados. Infecçôes congênitas (in útero) ou perinatais podem dar origem a infecçôes latentes, e a transmissão venérea ocorre sobretudo na espécie suína (MEGID et al., 2010).

As perdas econômicas advindas da infecção por $B$. abortus estáo relacionadas à baixa eficiência reprodutiva dos animais, à ocorrência de abortos e à alta frequência de natimortos e bezerros nascidos debilitados, que em geral morrem ou têm seu crescimento prejudicado, reduzindo o número de animais para comercialização. A diminuiçấo da produção de carne e leite é na ordem de $25 \%$, e o decréscimo da produção de bezerros em média de 15\% (BernuÉs et al., 1997; Miranda et al., 2008).

Segundo SANTOS et al. (2013), a cada 1\% de variação na taxa de prevalência de brucelose bovina no Brasil, estima-se em R \$ 155 milhôes o custo da doença. Essas perdas econômicas comprometem mais de $0,3 \%$ do produto interno bruto (PIB) brasileiro gerado por animais de produçáo.

A área de estudo desta pesquisa, a Regional de Pedreiras (MA), a qual está localizada na regiáo do Médio Mearim, é composta de 15 municípios e ocupa área de $7.738 \mathrm{~km}^{2}$, tem população de 237.363 habitantes e um rebanho bovídeo de 410.120 cabeças, distribuídos em 4.933 propriedades, com vocação natural para produção leiteira. É a terceira bacia leiteira do estado (IBGE, 2010).

Em razão da inexistência de estudos científicos sobre a prevalência da brucelose em rebanhos bovinos leiteiros e em humanos na Regional de Pedreiras, o presente trabalho teve por objetivos diagnosticar aglutininas anti-Brucella em bovinos e em grupos ocupacionais da cadeia produtiva do leite; e identificar fatores de risco associados à ocorrência da infecção por $B$. abortus em bovinos e em humanos nas propriedades amostradas mediante a aplicaçáo de questionário epidemiológico.

\section{MATERIAL E MÉTODOS}

Realizou-se um estudo observacional transversal na Regional de Pedreiras, no período de maio a outubro de 2013, com bovinos não vacinados contra brucelose, machos e fêmeas, com idade superior a 13 meses. Foram selecionadas propriedades com aptidão leiteira cadastradas na AGED-MA (AGED, 2012) nos municípios de Lago da Pedra, Igarapé Grande, Bernardo do Mearim, Poção de Pedras, Trizidela do Vale, Pedreiras e Lima Campos.

A fim de determinar o número de amostras de bovinos, foi utilizada metodologia preconizada pelo Centro Panamericano de Zoonoses para estudo de estimativa de prevalência, obtendo-se 525 amostras. Para cada um dos sete municípios, foram sorteados aleatoriamente cinco rebanhos, totalizando 35 . Também de forma aleatória simples, selecionaram-se 15 bovinos: 3 novilhas de reposição ( 13 a 24 meses), 4 vacas ( 25 a 36 meses), 7 vacas ( $>36$ meses) e 1 touro ( $\geq 36$ meses), totalizando 75 amostras por município.

As amostras de sangue foram colhidas por punção jugular, utilizando-se tubos de vácuo de $10 \mathrm{~mL}$, e transportadas sob refrigeraçáo para o Laboratório de Doenças Infecciosas do curso de Medicina Veterinária da Universidade Estadual do Maranhão (UEMA), onde foram centrifugadas por 5 minutos com força real de centrifugação igual a $1.000 \mathrm{G}$. As alíquotas de soro obtidas foram transferidas para tubos tipo Eppendorf e mantidas em temperatura de congelamento $\left(-20^{\circ} \mathrm{C}\right)$ até a realização dos exames sorológicos, conforme a Instrução Normativa $\mathrm{n}^{\circ}$ 6, de 8 de janeiro de 2004 (BRAsIL, 2004).

Os soros foram submetidos ao teste de triagem do antígeno acidificado tamponado (AAT), seguido dos testes confirmatórios 2-mercaptoetanol (2-ME) e polarização fluorescente (TPF) dos soros reagentes. $\mathrm{O}$ protocolo dos exames animais e a interpretação dos resultados do AAT e do 2-ME seguiram a Instruçáo Normativa no 41, de 24 de novembro de 2006 (BrasiL, 2006), sendo considerado soropositivo o animal que apresentasse reação ao 2-ME e, como foco, a propriedade cujo rebanho tivesse pelo menos um animal sororreagente. O TPF foi realizado com o Brucella abortus antibody test kit (Diachemix, Estados Unidos), sendo os resultados expressos em unidades de milipolarização $(\mathrm{mP})$ e interpretados da seguinte forma: negativo (até 9,9 mP), suspeito $(10,0$ a $20,0 \mathrm{mP})$ e positivo ( $>20,0 \mathrm{mP}$ ), conforme recomendação do fabricante.

O estudo foi aprovado e autorizado pela Comissão de Ética e Experimentação Animal (CEEA) do curso de Medicina Veterinária da UEMA sob no 022/2014.

Também se colheram hemossoros de 60 ordenhadores, de modo voluntário, após estes terem lido e assinado o termo de consentimento livre e esclarecido. As amostras de sangue foram colhidas por um auxiliar de enfermagem da Secretaria de Saúde, por punçáo da veia radial, com agulhas $25 \times 8 \mathrm{~mm}$, em tubos $(10 \mathrm{~mL})$, com sistema de vácuo, previamente identificados, e enviadas sob refrigeração para o laboratório da UEMA. 
Foi aplicado um questionário epidemiológico para avaliar potenciais fatores de risco: ocorrência de abortamentos, existência de outras espécies, procedimento com o animal que abortou, destino do feto e da placenta, realização de testes para diagnóstico de brucelose, compra de fêmeas e machos para reprodução, existência de piquete maternidade, consumo de leite cru, manipulação de fêmeas com dificuldades ao parto, vacinação contra brucelose.

Estimaram-se a frequência de focos (rebanhos com pelo menos um animal soropositivo para brucelose) e a frequência de animais soropositivos. Para a identificação dos fatores de risco, foi utilizado o modelo de regressão logística (Hosmer; Lemeshow, 1989), adotando-se o programa Stata 9.0. Realizou-se análise univariada selecionando-se as que apresentavam $\mathrm{p}<0,20$ no teste $\chi^{2}$, para integrarem o modelo multivariado, permanecendo as variáveis que indicaram $p<0,05$ na análise multivariada. Foram estimadas razóes de chance (OR) com intervalos de confiança (IC) de 95\%.

\section{RESULTADOS E DISCUSSÃO}

Das 525 amostras de soro bovino examinadas, obteve-se frequência de brucelose bovina, por teste, na ordem de 26/525 (4,95\%) no AAT, $17 / 525$ (3,23\%) no 2-ME e 13/525(2,47\%) no TPF.

A frequência de animais sororreagentes observada nesta pesquisa foi maior que a demonstrada por BorBA et al. (2012) no estado do Maranhão, com percentual de 2,52\%, e dos circuitos pecuários maranhenses: 1 (0,70\%), 3 (1,99\%) e $4(0,76)$. Porém, foi semelhante à prevalência do circuito 2 $(3,16 \%)$, onde está localizada a regiáo estudada. Esse resultado é por conta, provavelmente, da baixa cobertura vacinal, pois apenas $60 \%$ dos criadores realizam a vacinação. Dessa forma, recomendam-se aumentar a cobertura vacinal anual de bezerras entre três e oito meses com a estirpe B 19 para taxas $\geq 80 \%$ e estimular o uso da RB 51 nos focos. Em situaçóes de prevalência alta, segundo Paulim; Ferreira Neto (2003) recomendam que a cobertura vacinal mínima anual deve ser de $80 \%$, a fim de que a doença seja reduzida a níveis de $2 \%$ de prevalência. Segundo Amaku et al. (2009), para reduzir a prevalência da brucelose a $2 \%$ em uma determinada regiáo, é necessário obter coberturas vacinais acima de 70\%, imunizando os animais por um período de 10 anos.

Dos sete municípios amostrados, cinco apresentaram rebanhos com um ou mais animais reagentes nos testes confirmatórios, o que representa proporção de 5/7 (71,43\%) municípios com rebanhos foco de brucelose. Analisando-se os focos, verifica-se proporção de $9 / 35$ (25,71\%) e 8/35 (22,85\%) aos testes confirmatórios 2-ME e TPF, respectivamente.

A frequência de focos em rebanhos com pelo menos um animal soropositivo foi superior à encontrada por BoRBA et al. (2012), no estado do Maranhão (11,42\%).

Pelo teste de polarização fluorescente (TPF), as frequências de animais soropositivos e de focos foram 2,47 e 22,85\%, nessa ordem.

Vários fatores foram relacionados à presença de foco de brucelose nas propriedades, na análise univariada $(\mathrm{p}<0,20)$, destacando-se: presença de ovinos (OR=6,67; IC95\% 1,26$35,03)$; ocorrência de aborto nos últimos 12 meses $(\mathrm{OR}=2,81$; IC95\% 0,59-13,33); compra de animais para reprodução $(\mathrm{OR}=4,08$; IC95\% 0,70-23,50); e a presença de piquete maternidade (OR=0,26; IC95\% 0,04-1,63). Na análise multivariada foram incluídas as variáveis com $\mathrm{p}<0,05$. O modelo de regressão logística final mostrou que propriedades com presença de ovinos (OR=6,67; IC95\% 1,26-35,03) apresentavam maiores chances de terem pelo menos um bovino soropositivo (Tabela 1).

Tabela 1. Modelo de regressão logística univariada e multivariada dos fatores de risco mais associados à ocorrência de focos de brucelose bovina nas propriedades rurais amostradas na Regional de Pedreiras, MA, 2014.

\begin{tabular}{|c|c|c|c|c|c|c|c|}
\hline \multirow{3}{*}{ Variável } & \multicolumn{4}{|c|}{ Análise univariada } & \multicolumn{3}{|c|}{ Análise multivariada } \\
\hline & \multicolumn{4}{|c|}{ Rebanho/propriedade } & \multicolumn{3}{|c|}{ Propriedade } \\
\hline & Focos/expostos & $\%$ & OR & Valor $p^{*}$ & OR & IC95\% & Valor $p^{* *}$ \\
\hline \multicolumn{5}{|c|}{ Presença de ovinos } & 6,67 & $1,27-35,03$ & 0,025 \\
\hline Sim & $6 / 12$ & 50,00 & & & & & \\
\hline Não & $3 / 23$ & 13,04 & 6,67 & 0,025 & & & \\
\hline \multicolumn{8}{|c|}{ Presença de aborto nos últimos 12 meses } \\
\hline Sim & $5 / 13$ & 41,66 & & & & & \\
\hline Não & $4 / 22$ & 18,18 & 2,81 & 0,193 & & & \\
\hline \multicolumn{8}{|c|}{ Compra de animais para reprodução } \\
\hline Sim & $7 / 19$ & 36,84 & & & & & \\
\hline Não & $2 / 16$ & 12,50 & 4,08 & 0,115 & & & \\
\hline \multicolumn{8}{|c|}{ Presença de piquete maternidade } \\
\hline $\operatorname{Sim}$ & $6 / 29$ & 20,69 & & & & & \\
\hline Não & $3 / 6$ & 50,00 & 0,26 & 0,151 & & & \\
\hline
\end{tabular}

OR: odds ratio; ${ }^{*} \mathrm{p}<0,20 ;{ }^{* *} \mathrm{p}<0,05$; IC95\%: intervalo de confiança de $95 \%$. 
As informaçóes obtidas com a aplicação do questionário epidemiológico permitiram caracterizar a pecuária leiteira na Regional de Pedreiras com predominância da raça Girolando, criação tipo semiconfinamento, o que pode favorecer a ocorrência e a disseminação da doença em razáo da proximidade entre animais portadores e suscetíveis, conforme também atestaram Nicoletti (1980) e Crawford et al. (1990). A ordenhada é manual, uma vez ao dia, com bezerro ao pé, podendo estar associada com a transmissão da brucelose, pois o micro-organismo é eliminado pelo leite, e terneiros que se alimentam de vacas brucélicas podem contaminar o ambiente pela eliminação do agente com as fezes, uma vez que algumas bactérias não são destruídas pelas enzimas digestivas (LuCAs, 2006).

A idade $\geq 36$ meses em ambos os sexos foi fator determinante para a ocorrência da infecção nos dois testes confirmatórios. Isto é, quanto mais tempo de exposição ao agente infeccioso, maior a probabilidade de disseminação da bactéria, e ao adquirir imunidade o animal náo mais apresenta aborto entre o quinto e o oitavo mês de gestação.

A presença de ovinos, 12/35 (34,29\%), mostrou-se estatisticamente significativa, tanto no modelo de regressão logística univariada $(\mathrm{p}<0,20)$ quanto no de multivariada $(\mathrm{p}<0,05)$, demonstrando que propriedades com a presença de ovinos apresentavam 6,67 vezes mais chances de ser foco de brucelose. Isso se deve provavelmente pela criaçáo consorciada de bovinos e ovinos no mesmo piquete - na maioria das fazendas essas espécies são recolhidas ao entardecer e dormem juntas no mesmo curral, além de haver intensa movimentação dos ovinos para outras propriedades sem exigência do atestado de sanidade animal. Tal dado corrobora as observaçóes de Holt et al. (2011), que destacaram a importância da criação de bovinos e búfalos em conjunto com ovinos e caprinos (OR=6,32; IC95\% 1,44$27,9)$ no aumento do risco para brucelose bovina.

Outras espécies animais também podem ser infectadas por Brucella spp., incluindo búfalos, camelos, cavalos e renas; embora menos importantes, podem ser fonte de infecção expressiva em determinadas regiôes (CORBEL, 2006). Outros reservatórios incluem espécies silvestres, como o veado (Cervus elaphus), javali e porcos selvagens (Sus Scrofa), raposa (Vulpes Vulpes) e bisonte (Bison Bison) (Godfroid et al., 2005; Nicolleti, 2010).

A ocorrência de aborto nos últimos 12 meses foi relatada em 13/35 (37,14\%) e demonstrou ser fator importante na análise univariada. A ocorrência é indicativa de infecção e sugere que a brucelose é endêmica no rebanho.

A compra de animais para reprodução apresentou significância estatística na análise univariada $(\mathrm{p}<0,20)$. A aquisição era principalmente de outras fazendas, e na sua grande maioria não era exigido o exame sorológico negativo para brucelose, nem o conhecimento do estado sanitário do rebanho de origem.

De acordo com STRIGer et al. (2008), a aquisiçáo de animais infectados é relatada como o principal fator de introduçáo de brucelose em rebanhos livres. Conforme essa variável, alguns fatores atuam de forma independente ou associada, como: frequência de compra (prática comum em rebanhos leiteiros da região para aquisição de reprodutores e reposiçấo de matrizes), origem dos animais e histórico de realização de testes sorológicos para brucelose, observações também relatadas por Nicoleti (1980), Crawford et al. (1990) e LAGE et al. (2008). É importante frisar que a aquisição de novos animais significa risco real somente quando feita sem os devidos cuidados sanitários.

A variável existência de piquete maternidade foi importante na análise univariada $(\mathrm{p}<0,20)$. O piquete de parição é uma medida que deve ser implantada com o objetivo de evitar o contato de animais suscetíveis com fetos abortados, restos placentários e secreçóes vaginais, por possuir elevada concentração de Brucella, e podem contaminar pastagens e aguadas. Essa medida diminui a dose de desafio e interrompe o ciclo de transmissão da doença, afirmaram CRAWFORD et al. (1990). E é bem mais fácil realizar a desinfecção da área.

Outro dado relevante é que 24/35 (68,57\%) dos proprietários não separavam os animais que abortavam, deixando-os no plantel, aumentando com essa prática o risco de disseminação da doença no rebanho, pois não eliminavam os animais positivos. Somente $14,28 \%$ dos entrevistados disseram dar destino adequado à placenta e ao feto abortado, conduta que reduz o risco de contaminação ambiental e do contato desses materiais biológicos com animais suscetíveis (CRAWFOrd et al., 1990).

Dos 60 hemossoros humanos examinados, apenas um ordenhador, 1/60 (1,66\%), do município de Lago da Pedra, foi reagente nos testes confirmatórios 2-ME, TPF e FC.

CoÊLho et al. (1995) e SANTOS et al. (2007), no município de São Luís, constataram prevalências de 2,17\% e 10,71\% dos trabalhadores de matadouros reagentes na prova de FC e no teste do 2-ME, respectivamente. Esses autores observaram mais ocorrência de pessoas reagentes nos setores de matança e evisceração.

Outro aspecto importante refere-se ao risco zoonótico que a brucelose representa. Nos seres humanos pode ser uma doença grave, debilitante e muitas vezes levar à cronicidade, podendo afetar vários órgãos. A maioria dos casos é por exposição ocupacional aos animais infectados, ingestão de leite cru e de produtos lácteos não pasteurizados e acidentes vacinais (Brasil, 2006; LAGe et al., 2008; Megid et al., 2010). Os sinais mais comuns são febre ondulante, suores noturnos com peculiar odor, calafrios, fraqueza, insônia, artralgia, dores musculares e testiculares, impotência sexual, nervosismo e depressão (Acha; Szyfres, 2001; SANtos et al., 2005; LAGE et al., 2008; Megid et al., 2010; Poester, 2010).

Dos 60 ordenhadores entrevistados do sexo masculino, $90 \%$ afirmaram ter mais de cinco anos como tratador, podendo estar exposto durante esse período ao agente infeccioso; e 45/60 $(71,43 \%)$ manipulavam vacas com dificuldades ao parto e não usavam equipamentos de proteção individual, mantendo contato com fetos abortados, restos placentários e secreçôes 
vaginais. Dessa forma, ficavam expostos à infecçáo, podendo o risco ser caracterizado pelo contato direto de abrasóes da pele com tecidos de animais infectados ou por via respiratória, pela inalação de aerossóis, conforme relataram FeRRAZ (1999), Doganay; Aygen (2003) e Franzolin (2005).

Quando questionados sobre a sintomatologia clínica da brucelose, 50/60 (83,33\%) afirmaram ter apresentado um ou mais sintomas como febre, dor de cabeça, cansaço, calafrios, sudorese noturna, mialgia e artralgia. $\mathrm{O}$ ordenhador reagente relatou, ainda, dores testiculares, irritabilidade e nervosismo.

Abordados quanto o hábito de ingerir leite cru, 48/60 $(80 \%)$ dos tratadores responderam sim. Essa é uma real exposiçáo, pois Brucella spp. pode ser isolada do leite de vacas positivas (LANGONi et al., 2000).

Quando questionados se já vacinaram contra brucelose, 20/60 (33,33\%) afirmaram que sim, sem terem passado por nenhum treinamento prévio realizado pelo veterinário cadastrado, bem como vacinaram sem uso de equipamentos de proteção individual (EPIs). Fato relevante, pois as amostras vacinais B 19 e RB 51 de B. abortus são patogênicas para humanos, podendo ocorrer transmissão ao trabalhar com vacinas vivas (Berkelman, 2003; Mathias, 2008), principalmente pela exposição acidental ao líquido contido no frasco e pela perfuração do dedo com a agulha durante a aplicação.

De acordo com o Sistema de Informações Hospitalares do Sistema Único de Saúde (SIH/SUS), do Ministério da Saúde, de janeiro de 2008 a março de 2014 ocorreram 177 internaçóes por causa de brucelose, no âmbito do SUS, sendo 62 na região Sul, 54 na regiáo Sudeste, 27 na região Nordeste, 23 na região Norte e 11 na regiáo Centro-Oeste. Aconteceram oito óbitos durante esse período: cinco na regiāo Sul, dois na região Nordeste e um na região Sudeste (BrasIL, 2014). Ressalta-se que a brucelose humana, por ser de difícil diagnóstico, é uma doença subnotificada e de pouca visibilidade pelas autoridades sanitárias no Brasil, muito embora seja de notificação obrigatória.

\section{CONCLUSÃO}

Com base nos resultados obtidos, conclui-se:

- as frequências de animais sororreagentes e de foco de brucelose na Regional de Pedreiras foram elevadas;

- o principal fator de risco associado à presença de foco no rebanho foi a criaçáo consorciada de bovinos com ovinos, prescindindo de investigação epidemiológica para B. abortus em ovinos e se estes estáo atuando como reservatório da brucelose bovina;

- foi diagnosticada brucelose humana na regiáo pesquisada.

Há necessidade de educação sanitária para conscientizar os criadores sobre os impactos negativos que essa doença acarreta para a saúde pública e animal. REFERÊNCIAS

ACHA, P.N.; SZYFRES, B. Zoonosis y enfermidades transmisibles comunes al hombre y a los animales: Bacteriosis y Micosis. 3rd.ed. Washington: Organización Panamericana de la Salud, 2001. p.28-55.

AGÊNCIA ESTADUALDE DEFESA AGROPECUÁRIA DO MARANHÃO. Coordenadoria de Defesa Animal. Programa de Prevenção e Erradicação da Febre Aftosa. Estratificação do rebanho bovino leiteiro da Regional de Pedreiras. Jun. 2012. (Relatório final da $1 .^{a}$ etapa de vacinação dos bovinos contra febre aftosa no Maranhão).

AMAKU, M.; DIAS, R.A.; FERREIRA NETO, J.S.; FERREIRA F. Modelagem matemática do controle de brucelose bovina por vacinação. Arquivo Brasileiro de Medicina Veterinária e Zootecnia, v.61, Suppl.1, p.135-141, 2009.

BERKELMAN, R.L. Human illness associated with use of veterinary vaccines. Clinical Infection Diseases, Chicago, v.37, n.3, p.407-424, 2003.

BERNUÉS, A.; MANRIQUE, E.; MAZA, M.T. Economic evaluation of bovine brucellosis and tuberculosis eradication programmes in a mountain area of Spain. Preventive Veterinary Medicine, v.30, n.2, p.137-149, 1997.
BORBA, M.R.; STEVENSON, M.A.; GONÇALVES, V.S.P.; FERREIRA NETO, J.S.; FERREIRA, F.; AMAKU, M.; TELLES, E.O.; SANTANA, S.S.; FERREIRA, J.C.A.; LÔBO, J.R.; FIGUEIREDO, V.C.F.; DIAS, R.A. Prevalence and risk-mapping of bovine brucellosis in Maranhão State, Brazil. Preventive Veterinary Medicine, v.110, n.2, p.169-176, 2013.

BRASIL. Ministério da Agricultura, Pecuária e Abastecimento. Instrução Normativa n. ${ }^{\circ}$ 2, de 10 de janeiro de 2001. Institui o Programa Nacional de Controle e Erradicação da Brucelose e Tuberculose Animal. Diário Oficial da União, Brasília, 10 jan. 2001.

BRASIL. Ministério da Agricultura, Pecuária e Abastecimento. Secretaria de Defesa Agropecuária. Departamento de Saúde Animal. Manual Técnico do Programa Nacional de Controle e Erradicação da Brucelose e da Tuberculose Animal (PNCEBT). Brasília: MAPA/SDA/DAS, 2006.

BRASIL. Secretaria de Defesa Agropecuária, Ministério da Agricultura, Pecuária e Abastecimento. Instrução Normativa n. ${ }^{\circ}$, de 8 de janeiro de 2004. Aprova o Regulamento Técnico do Programa Nacional de Controle e Erradicação da Brucelose e Tuberculose Animal. Diário Oficial da União, Brasília, 12 jan. 2004. p.6-10. 
BRASIL. Ministério da Saúde. DATASUS. Morbidade hospitalar do SUS por local de residência - Brasil: lista morbidade CID-10: brucelose. Internações, óbitos e média de permanência em internação por ano processamento segundo região. 20082014. Disponível em: <http://tabnet.datasus.gov.br/cgi/tabcgi. exe?sih/cnv/nruf.def>. Acesso em: 26 jun. 2014.

COELHO, L.M.; MARTINS, L.; EVANGELISTA, F.H. Prevalência da brucelose nos trabalhadores de matadouro em São Luís, estado do Maranhão. Revista Brasileira de Medicina Veterinária, Rio de Janeiro, v.17, n.2, p.85-88, 1995.

CORBEL, M.J. Brucellosis in humans and animals. World Health Organization, 2006. Disponível em: <http://www.who.int/ $\mathrm{crs} /$ resourcest/publications/Brucellosis.pdf $>$. Acesso em: 15 abr. 2014.

CRAWFORD, R.P.; HUBER, J.D.; ADAMS, B.S. Epidemiology and surveillance. In: NIELSEN, K.; DUNCAN, J.R. (Eds.). Animal brucellosis. Boca Raton: CRC Press, 1990. p.131-151.

DOGANAY, M.; AYGEN, B. Human brucellosis: an overview. International Journal of Infectious Diseases, v.7, n.3, p.173-182, 2003. Disponível em: <http://www.ijidonline. com/article/S1201-9712(03)90049-X/pdf >. Acesso em: 5 jan. 2014.

FERRAZ, I.B.F. Novos métodos de controle e diagnóstico da brucelose bovina. Revista Brasileira de Reprodução Animal, v.23, n.4, p.504-508, 1999.

FRANZOLIN, M.R. Brucella e Francisella. In: TRABULSI, L.R.; ALTHERTHUM, F. (Eds.). Microbiologia. 4th.ed. São Paulo: Ateneu, 2005. chap.33. p.261-263.

GODFROID, J.; CLOECKAERT, A.; LIAUTARD, J.P.; KOHLER, S.; FRETIN, D.; WALRAVENS, K.; GARIN-BASTUJI, B.; LETESSON, J.J. From the discovery of the Malta fever's agent to the discovery of a marine mammal reservoir, brucellosis has continuously been a re-emerging zoonosis. Veterinary Research, v.36, n.3, p.313-326, 2005.

GOMES, M.J.P. Gênero Brucella spp. Rio Grande do Sul: FAVET-UFRGS, 2013. Disponível em: <http://www.ufrgs.br/ labacvet/files/G\%C3\%AAnero\%20Brucella\%204-2013-1. pdf $>$. Acesso em: 25 mar. 2014.

HOLT, H.R.; ELTHOLTH, M.M.; HEGAZY, Y.M., EL-TRAS, W.F.; TAYEL, A.A.; GUITIAN, J. Brucella spp. infection in large ruminants in an endemic area Egypt: cross-sectional study investigating seroprevalence, risk factors and livestock owner's knowledge, attitudes and practices (KAPs). BMC Public Health, v. 11 , p.341, 2011.

HOSMER, D.W.; LEMESHOW, S. 1989. Applied logistic regression. 2nd.ed. New York: Wiley-Interscience Publication, 2000. 397p.

INSTITUTO BRASILEIRO DE GEOGRAFIA E ESTATÍSTICA. 2010. Disponível em: <http://www.ibge.gov.br>. Acesso em: 15 abr. 2014.
LAGE, A.P.; POESTER, F.P.; PAIXÃO, T.A.; SILVA, T.M.A.; XAVIER, M.N.; MINHARRO, S.; MIRANDA, K.L.; ALVES, C.M.; MOL, J.P.S.; SANTOS, R.L. Brucelose bovina: uma atualização. Revista Brasileira de Reprodução Animal, Belo Horizonte, v.32, n.3, p.202-212, jul./set. 2008. Disponível em: <http://www.cbra.org.br>. Acesso em: 4 jan. 2014.

LANGONI, H.; ICHIHARA, S.M.; SILVA, A.V.; PARDO, R.B.; TONIN, F.B.; MENDONÇA, L.J.P.; MACHADO, J.A.D. Isolation of Brucella spp. from milk of brucellosis positive cows in São Paulo and Minas Gerais states. Brazilian Journal of Veterinary Research and Animal Science, São Paulo, v.37, n.6, p.444-448, 2000.

LUCAS, A. Simulação de impacto econômico da brucelose bovina em rebanhos produtores de leite das regiões Centro-Oeste, Sudeste e Sul do Brasil. 2006. 123f. Tese (Doutorado em Epidemiologia Experimental e Aplicada às Zoonoses) - Universidade de São Paulo, São Paulo, 2006.

MATHIAS, L.A. Brucelose animal e suas implicações em saúde pública. Biológico, São Paulo, v.70, n.2, p.47-48, 2008.

MEGID, J.; MATHIAS, L.A.; ROBLES, C.A. Clinical manifestations of brucellosis in domestic animals and humans. The Open Veterinary Science Journal, v.4, p.119-126, 2010.

MIRANDA, K.L.; ALVES, C.M.; MINHARRO, S.; LÔBO, J.R.; MÜLLER, E.E.; GONÇALVES, V.S.P.; LAGE, A.P. Quem ganha com a certificação de propriedades livres ou monitoradas pelo PNCEBT? Leite Integral, v.3, p.44-55, 2008.

NICOLETTI, P. The epidemiology of bovine brucellosis. Advances in Veterinary Science and Comparative Medicine, v.24, p.69-98, 1980.

NICOLETTI, P. Brucellosis: past, present and future. Prilozi, v.31, n. 1, p.21-32, 2010 .

PAULIN, L.M.; FERREIRA NETO, J.S. O combate à brucelose bovina: situação brasileira. Jaboticabal: FUNEP, 2003. 154p.

POESTER, F.P. Brucelose. 2010. Disponível em: <http:// www.zoonoses.org.br/absoluto/midia/imagens/zoonoses/ arquivos_1258561628/3644_manual_de_zoonoses_v1_ edicao2.pdf > . Acesso em: 2 fev. 2014.

SANTOS, H.P.; TEIXEIRA, W.C.; OLIVEIRA, M.M.M.; PEREIRA, H.M.; OLIVEIRA, R.A.; NEGREIROS, R.C.; SOARES FILHO, P.M.; SANTANA, S.S.; CASTRO, R.S. Brucelose bovina e humana diagnosticada em matadouro municipal de São Luís - MA, Brasil. Ciência Veterinária nos Trópicos, Recife, v.10, n.2/3, p.86-94, 2007.

SANTOS, R.L.; POESTER, F.P.; LAGE, A.P. Infecção por Brucella ovis. Caderno Técnico de Veterinária e Zootecnia, n.47, p.42-56, 2005.

SANTOS, R.L.; MARTINS, T.M.; BORGES, A.M.; PAIXÃO, T.A. Economic losses due to bovine brucellosis in Brazil. Pesquisa Veterinária Brasileira, v.33, n.6, p.759-764, jun. 2013.

STRINGER, L.A.; GUITIAN, F.J.; ABERNETHY, D.A.; HONHOLD, N.H.; MENZIES, F.D. Risk associated with animals moved from herds infected with brucellosis in Northern Ireland. Preventive Veterinary Medicine, v.84, p.72-84, 2008. 